\title{
Anthropogenic climate change has changed frequency of past flood during 2010-2013
}

\author{
Yukiko Hirabayashi ${ }^{{ }^{*}}$ (D), Haireti Alifu', Dai Yamazaki ${ }^{2}$, Yukiko Imada ${ }^{3}$, Hideo Shiogama ${ }^{4}$ and Yuki Kimura ${ }^{5}$
}

\begin{abstract}
The ongoing increases in anthropogenic radiative forcing have changed the global water cycle and are expected to lead to more intense precipitation extremes and associated floods. However, given the limitations of observations and model simulations, evidence of the impact of anthropogenic climate change on past extreme river discharge is scarce. Here, a large ensemble numerical simulation revealed that 64\% (14 of 22 events) of floods analyzed during 2010-2013 were affected by anthropogenic climate change. Four flood events in Asia, Europe, and South America were enhanced within the 90\% likelihood range. Of eight snow-induced floods analyzed, three were enhanced and four events were suppressed, indicating that the effects of climate change are more likely to be seen in the snow-induced floods. A global-scale analysis of flood frequency revealed that anthropogenic climate change enhanced the occurrence of floods during 2010-2013 in wide area of northern Eurasia, part of northwestern India, and central Africa, while suppressing the occurrence of floods in part of northeastern Eurasia, southern Africa, central to eastern North America and South America. Since the changes in the occurrence of flooding are the results of several hydrological processes, such as snow melt and changes in seasonal and extreme precipitation, and because a climate change signal is often not detectable from limited observation records, large ensemble discharge simulation provides insights into anthropogenic effects on past fluvial floods.
\end{abstract}

Keywords: Floods, Event attribution, Large ensemble numerical simulations

\section{Introduction}

Flooding is a common major natural hazard in many areas of the world, and its frequency and magnitude are expected to increase with climate warming. Previous studies indicated that flood frequency is non-stationary (Milly et al. 2008; Villarini et al. 2009), although many water management designs have assumed that flood occurrence or magnitude is stationary based on patterns observed in the past. Therefore, it is important to analyze changes in the frequency and magnitude of flooding to develop adequate adaptation and mitigation strategies. For this purpose, flood changes associated with climate change have been projected in the near (e.g., 2030-2050) and far

\footnotetext{
* Correspondence: hyukiko@shibaura-it.ac.jp

${ }^{1}$ Department of Civil Engineering, Shibaura Institute of Technology, 3-7-5

Toyosu, Koto-ku, Tokyo 135-8548, Japan

Full list of author information is available at the end of the article
}

(-2100) future, driven by anthropogenic climate change scenarios (Dottori et al. 2018; Hirabayashi et al. 2013; Hirabayashi et al. 2021); often, the results of the warmest scenario (e.g., RCP8.5) have been used to capture a prominent climate change signal.

The effect of climate change on flooding can also be evaluated by detecting and attributing past changes in flooding in historical data. Due to smaller signals in the lower level of warming in the recent past compared to future projections, many climate simulations with and without anthropogenic climate change since the industrial revolution have been compared to evaluate the effects of past anthropogenic effects on climate change. For example, the effects of human-induced global warming on past heavy precipitation events (Imada et al. 2020; Li et al. 2021) and mean and extreme streamflow (Gudmundsson et al. 2021) have been investigated using large 
ensemble climate simulations. Despite evidence of a general increase in extreme precipitation events in the past (Hartmann et al. 2013; Min et al. 2011), the observed changes in flooding vary with catchment sizes or hydroclimatological characteristics (Do et al. 2017; Sharma et al. 2018). Small catchments often show changes similar to those of precipitation (Do et al. 2017), whereas other changes associated with warming, such as decreases in soil moisture and snow melt, might be dominant in larger catchments (Bloeschl et al. 2019; Sharma et al. 2018). Historical human intervention could alter natural flood changes. Due to the difficulties in attribution because of the complexity of drivers of change in river discharge (Madsen et al. 2014; Trenberth et al. 2015), large-scale perspectives on potential impacts of anthropogenic activities on the probability of historical flood events that include these regions could have significant policy implications. As most climatic attribution studies have focused on single-step direct output of climate models (e.g., temperature and precipitation), few studies have investigated event attribution to river flooding. Since studies of flood projection (Hirabayashi et al. 2013; Hirabayashi et al. 2021; Sharma et al. 2018) have demonstrated that the direction of the changes (wet or dry) in precipitation and flooding is not consistent in spatiotemporally because of several hydrological processes, event attribution of river discharge will enhance our understanding of the effects of climate change on flood risk.

This study evaluated the impact of anthropogenic climate change on the probability of historical large flood events based on river discharge derived from large ensemble climate experiments to investigate whether possible mechanisms of the past changes in floods due to climate change have already been revealed. For this purpose, we analyzed 22 flood events occurring during the target period at a global scale, rather than focusing on specific flood events, to provide an overview of the effects of past anthropogenic climate change on flood events.

\section{Data and methods}

\subsection{Event attribution of historical floods between 2010 and 2013}

Modeled discharges obtained from a global river and inundation model-the Catchment based Macro-scale Floodplain (CaMa-Flood) model (Yamazaki et al. 2011), driven by runoff data from a large-ensemble climate experiment with (hereafter referred to as "ALL") and without ("NAT") anthropogenic radiative forcing (Shiogama et al. 2013) were used for event attribution of historical flood from 2010 to 2013 (Table 1). A large-ensemble climate experiment was conducted using an atmospheric general circulation model (AGCM) MIROC5 (Watanabe et al. 2010) driven by sea surface temperature (SST), sea ice, and historical external forcing factors.

Three types of experiment were performed in this study (Table 1). ALL-LNG was a ten member ensemble run of the AGCM driven by observed SST, sea ice, and historical anthropogenic and natural external forcing between 1949 and 2013. The 100-member ensemble runs of ALL were produced with the same anthropogenic and natural external conditions as the ALL-LNG runs. NAT was a 100-member ensemble run produced under natural external conditions. To analyze the uncertainties in removing anthropogenic signals from SST and sea ice data, two NAT experiments (NAT-dtr and NAT-cmip5) were used for the analysis (Shiogama et al. 2014).The main difference between the experiments is SST without historical climate change used as a boundary condition (See Supporting Information S1 for the details of the experiments).

The daily runoff output of the experiments with a spatial resolution of T85 (approximately $133 \mathrm{~km}$ at the equator) was simply interpolated and then integrated to river discharge through a high-resolution $\left(15^{\prime} \times 15^{\prime}\right)$ global river network map from the CaMa-Flood model. Subsequently, the annual maximum daily discharge was obtained for each experiment. The annual maximum daily discharge data calculated using ALL-LNG (total, 650 members from ten ensembles annually between 1949 and 2013) were used to define flood events corresponding to a 10 -year flood, i.e., floods with probability $>0.1$ in any given year for each $15^{\prime} \times 15^{\prime}$-grid cell, by fitting the data to the Gumbel probability distribution function using the L-moment method (Supplementary Information S3).

Twenty-two historical flood events that occurred during the period were selected from the Emergency Events Database (EM-DAT n.d.), news media, or streamflow records (Supporting Information S2). Events were selected only if the flood probability under the historical simulation of ALL at the specific location and year, corresponding to the selected flood events, was higher than that of long-term experiments (ALL-LNG). This outcome indicated that the flooding for a particular location in a particular year did not occur purely by chance. A flood was defined as when the return periods of the annual maximum daily discharge in all samples of ALLLNGs were longer than 10 years - (i.e., 10-year floods).

The fraction of attributable risk (FAR) can quantify the human influence on the occurrence of individual recent historical events, such as heat waves, droughts (Lewis and Karoly 2013; Otto et al. 2012; Shiogama et al. 2013; Stott et al. 2005), heavy precipitation (Min et al. 2011; Sippel and Otto 2014), and floods (Pall et al. 2011). We calculated FAR as $\left(\mathrm{P}_{\mathrm{A}}-\mathrm{P}_{\mathrm{N}}\right) / \mathrm{P}_{\mathrm{A}}$, where $\mathrm{P}_{\mathrm{A}}$ and $\mathrm{P}_{\mathrm{N}}$ represent the probability of a flood exceeding the 
Table 1 Summary of event attribution climate experiments. SST, sea surface temperature; ALL, large-ensemble climate experiment with anthropogenic radiative change; ALL-LNG, ALL experiment forcing long period runs; NAT, large-ensemble climate experiment without anthropogenic radiative forcing

\begin{tabular}{lllll}
\hline & Ensemble members & Time period & External forcing & SST and sea ice cover \\
\hline ALL-LNG & 10 & $1949-2013$ & All historical forcing & Observation $^{a}$ \\
ALL & 100 & $2010-2013$ & All historical forcing & Observation \\
NAT (NAT-dtr and NAT-cmip5) & 100 & $2010-2013$ & Natural forcing & Anthropogenic signals are removed from observed data \\
\hline
\end{tabular}

a(Rayner et al. 2003)

magnitude of the flood (10-year flood in ALL-LNG experiment) for the ALL and NAT experiments, respectively. The occurrence of floods was enhanced (suppressed) by human influence if FAR was positive (negative). Due to lower warming levels in the past records, the probability of change shown by FAR enables us to attribute the effects of climate change on the occurrence of flooding. The anthropogenic influence on floods remained uncertain when NAT-dtr and NATcmip5 experiments yielded FAR values with opposite signs. To evaluate the uncertainty of FAR, we conducted uncertainty analysis based on a bootstrap method; the significance of the FAR signal (positive or negative) was tested using nonparametric bootstrap samples (Efron and Tibshirani 1993). A random member generator was used to sample a $50 \%$ subset of the annual maximum daily discharge from the 100 ensembles when and where the flood event was observed. This procedure was repeated 1000 times, giving 1000 estimates of FAR for each experiment (ALL, NAT-dtr, and NAT-cmip5). To indicate the spread of the FAR values, we provided two estimates of the FAR value, those exceeding $50 \%$ (best estimate; $\mathrm{FAR}_{50}$ ) and $90 \%$ (very likely; $\mathrm{FAR}_{90}$ ) of the values in the bootstrapped FAR distributions. FAR values are reported as here as $F_{A R}$ and $F A R_{90}$. The value of the 10th (90th) percentile of FAR (Table S1) is shown as $\mathrm{FAR}_{90}$ when $\mathrm{FAR}_{50}$ is positive (negative). The same signal of $\mathrm{FAR}_{50}$ and $\mathrm{FAR}_{90}$ values (positive or negative) indicate that past anthropogenic climate change has affected the occurrence of analyzed flood events with a $90 \%$ probability. Compared with standard climate projection studies, event attribution and assessment using FAR imposes the effects of anthropogenic climate change on past flood events with uncertainty of the attribution. We interpreted $\mathrm{FAR}_{50}$ values (positive or negative) between the different NAT experiments (NAT-dtr and NAT-cmip5) to indicate that the effect of climate change on the event was unclear within the uncertainty of past simulations.

To evaluate changes in the occurrence of flooding for the period 2010-2013 at global scale, we calculated the average $\mathrm{FAR}_{50}$ values for all sub-catchments of large river basins. The probability of a flood exceeding a 10year flood among 100 samples was calculated at the outlet of each sub-catchment for each year and then averaged for the entire period. Finally, the average $F \mathrm{R}_{50}$ for NAT-dtr and NAT-cmip5 were calculated and presented.

\subsection{River discharge data}

Data on the observed daily discharge were obtained from the Global Runoff Data Centre (https://www.bafg.de/ GRDC/EN/Home/homepage_node.html). Since the spatial resolution of climate models cannot resolve small river basins, only relatively large river basins (area $>100,000 \mathrm{~km}^{2}$ ) with at least 30 years of observed daily discharge data (within the period 1975-2015) were selected. We used data only when data were missing for fewer than 73 days in the year (20\% of the year).

Global daily discharge reanalysis for the same period was obtained from CaMa-Flood, which simulates floodplain inundation dynamics in a realistic manner and improves the predictability of river discharge at high temporal and spatial resolutions (Yamazaki et al. 2011). Daily runoff input for the simulation was obtained from a land surface model, Minimal Advanced Treatment of Surface Interaction and Runoff (MATSIRO) simulation (Koirala et al. 2014; Takata et al. 2003), which is forced by a bias-corrected global reanalysis, i.e., S14FD (Iizumi et al. 2017). The annual maximum daily discharge of the reanalysis had a slightly large spread (Fig. S2), but was also reasonable correlation at many basins (Fig. S3). Among 136 selected catchments, 46 (34\%) show correlation higher than 0.6 and $65(48 \%)$ show correlation higher than 0.5. Large bias occurred for catchments with averaged observed discharge less than $2400 \mathrm{~m}^{3} / \mathrm{s}$. The proportion of gauges with less than $50 \%$ bias increased from $41 \%$ in the entire group to $82 \%$ for the group with large discharges. The proportion of bias less than $20 \%$ increased from 20 to $43 \%$. Possible reasons of the discrepancies in peak discharge is human interventions or model's limitations including quality of climate forcing and hydrological processes such as freezing in cold rivers (Hirabayashi et al. 2013). It should be noted that our model chain does not take into account human regulation of rivers, such as reservoir operation and irrigation intake, or land-use changes. Hence, the modeled daily discharges of the event attribution experiment and 
reanalysis differ from the observed discharge under intensive human water management.

\section{Results and Discussion}

\subsection{Evaluation of large ensemble climate experiments}

We evaluated the model performance by comparing observed and simulated discharges. As the limited number of ensemble climate experiments does not necessarily produce observations matching time series, the ranges of ten ensemble long-term historical experiments (ALLLNG) and their ensemble mean are shown (Fig. S4 and S5). The long-term daily discharge reanalysis (S14FD) is also plotted. Comparisons of the annual maximum daily discharge derived from observations and long-term historical experiments (ALL-LNG) indicated that the climate model output and our modeling framework have several potential biases. For the 12 basins for which observations were available (red lines in Fig.S3), five (the Mississippi, Amazon, Danube, Volga, and Fitzroy Basins) had similar magnitudes and seven (the Mackenzie, Peace, Fraser, Saskatchewan, Red, Missouri, and Okavango Basins) overestimated the annual maximum daily discharge. Since discharge reanalyses also showed overestimation and had magnitudes similar to ALL-LNG in all these basins except for the Fraser and Okavango, the overestimation is thought to be the effect of human activities, such as reservoir operations or irrigation intake, which are not implemented either the reanalyses or ALL-LNG simulations. The overestimations for the Fraser and Okavango Rivers may be caused by bias in the precipitation output of climate experiments.
The cumulative distribution function (CDF) of the annual maximum daily discharge of flood events suggested that the observed distribution of the annual maximum daily discharge was within the probable range of the longterm event attribution experiment (ALL-LNG) in five basins (Mississippi, Amazon, Volga, Yalu, and Fitzroy) of the 12 basins for which observations were available (black lines in Fig. S5). The remaining seven basins (the Mackenzie, Peace, Fraser, Saskatchewan, Red, Missouri, and Okavango) showed overestimation of CDF. Most of these basins also showed smaller annual fluctuations in the annual maximum daily discharge, perhaps due to human water management. Despite the biases in magnitude in these basins, the ALL-LNG experiment reasonably reproduced the fluctuations in the annual maximum daily discharge in most basins (Fig. S2 and S5).

\subsection{Anthropogenic radiative effect on the occurrence of past floods}

The results of $\mathrm{FAR}_{50}$ indicated that ongoing climate change affected the occurrence of $64 \%$ (14 of 22) of historical floods from 2010 to 2013 (Fig. 1, Table 2); they were enhanced in eight basins and suppressed in six. Anthropogenic radiative forcing increased the occurrence of eight floods in Asia, Europe, North America, and South America within the 90\% likely range (Table 2). Of these, the cause of five flood events (Magdalena in 2011, Amazon in 2012, Amur in 2013, Songhua in 2013, and Indus in 2010) was heavy rainfall, corresponding to the observed significant increases in heavy precipitation on a global scale (Dunn et al. 2020), which has been shown to be the result of anthropogenic changes (Min

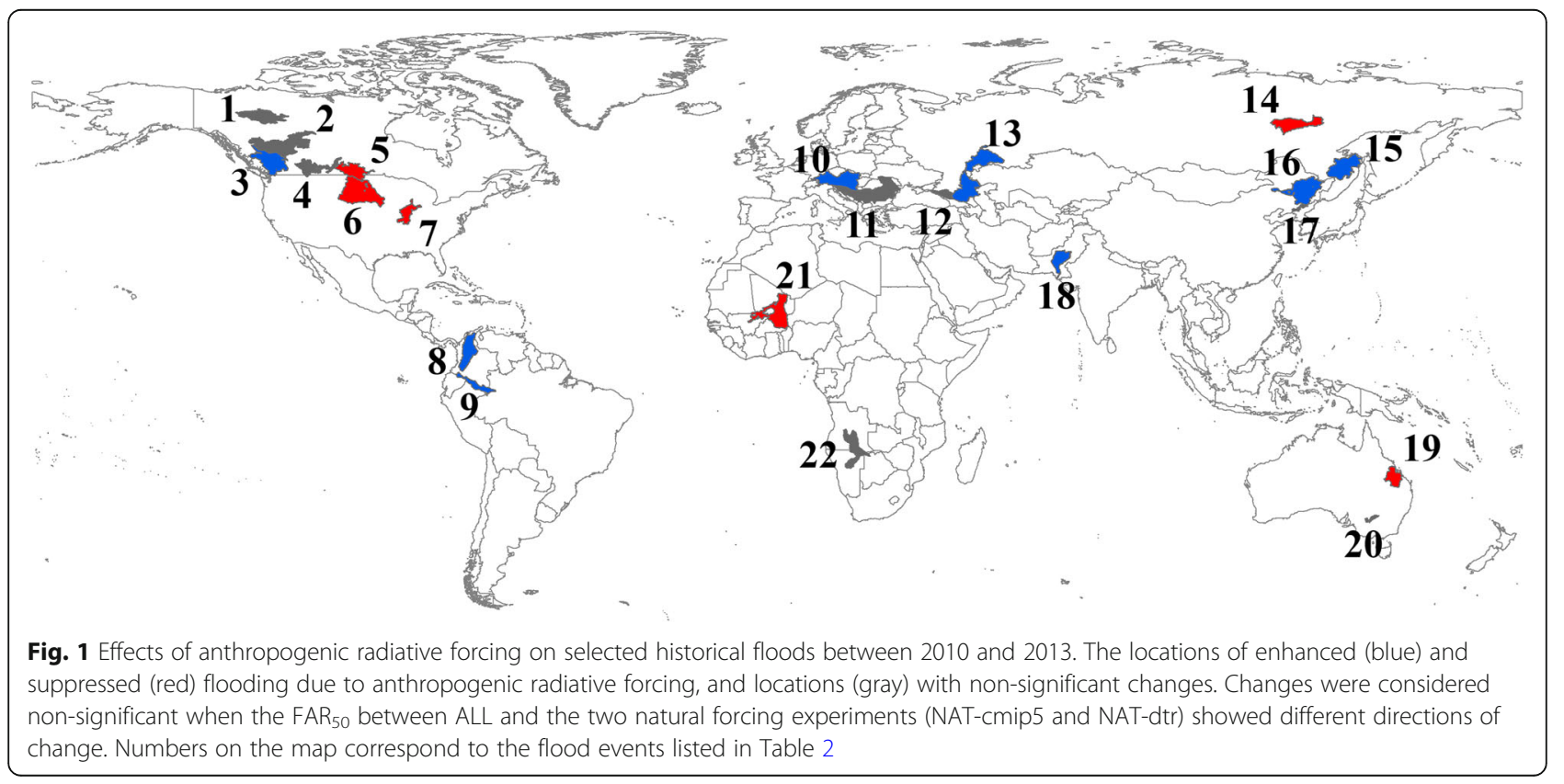


Table 2 Summary of selected flood events between 2010 and 2013. The effects of anthropogenic climate change on flood events ( $E$, enhanced; S, suppressed; N/A, no significant effect) were judged as $E(S)$ when both fraction of attribution (FAR ${ }_{50}$ ) scores between ALL and NAT_dtr (dtr) and those between ALL and NAT_CMIP5 (CMIP5) show the same signal. The value of the 10th (90th) percentile of FAR (Table S1) is shown as FAR ${ }_{90}$ when $F A R_{50}$ is positive (negative)

\begin{tabular}{|c|c|c|c|c|c|c|c|}
\hline \multirow[t]{2}{*}{ 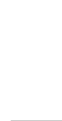 } & \multirow[t]{2}{*}{ River } & \multirow[t]{2}{*}{ Region } & \multirow[t]{2}{*}{ Year } & \multirow[t]{2}{*}{ Causes } & \multicolumn{2}{|l|}{ FAR } & \multirow[t]{2}{*}{ Effect } \\
\hline & & & & & $\begin{array}{l}\text { dtr } \\
\text { 50th/90th percentile }\end{array}$ & $\begin{array}{l}\text { CMIP5 } \\
\text { 50th/90th percentile }\end{array}$ & \\
\hline 1 & Mackenzie & NA & 2012 & Snow melt, heavy rain & $0.44 / 0.17$ & $-0.17 / 0.24$ & N/A \\
\hline 2 & Peace & NA & 2011 & Heavy rain & $0.14 /-0.42$ & $-0.29 / 0.18$ & N/A \\
\hline 3 & Fraser & NA & 2012 & Snow melt & $0.36 / 0.08$ & $0.01 /-0.52$ & E \\
\hline 4 & Saskatchewan & NA & 2013 & Heavy rain & $0.11 /-0.34$ & $-0.11 / 0.35$ & N/A \\
\hline 5 & Red & NA & 2011 & Snow melt & $-0.92 /-0.26$ & $-0.49 / 0.01$ & S \\
\hline 6 & Missouri & NA & 2011 & Snow melt & $-0.30 / 0.17$ & $-0.07 / 0.37$ & S \\
\hline 7 & Mississippi & NA & 2011 & Snow melt, storm & $-0.29 / 0.27$ & $-0.46 / 0.13$ & S \\
\hline 8 & Magdalena & SA & 2011 & Heavy rain & $0.46 / 0.16$ & $0.30 /-0.02$ & E \\
\hline 9 & Amazon & SA & 2012 & Heavy rain & $0.45 / 0.24$ & $0.48 / 0.24$ & E \\
\hline 10 & Sava & EU & 2010 & Snow melt, heavy rain & $0.09 /-0.54$ & $0.36 /-0.17$ & E \\
\hline 11 & Danube & EU & 2013 & Heavy rain & $-0.01 / 0.38$ & $0.28 /-0.19$ & N/A \\
\hline 12 & Kuban & EU & 2012 & Storm & $0.65 / 0.31$ & $-0.24 / 0.28$ & N/A \\
\hline 13 & Volga & EU & 2012 & Snow melt & $0.27 / 0.01$ & $0.35 / 0.12$ & E \\
\hline 14 & Lena & AS & 2010 & Snow melt & $-0.07 / 0.32$ & $-0.12 / 0.24$ & S \\
\hline 15 & Amur & AS & 2013 & Heavy rain & $0.54 / 0.25$ & $0.45 / 0.15$ & E \\
\hline 16 & Songhua & AS & 2013 & Heavy rain & $0.63 / 0.37$ & $0.48 / 0.17$ & E \\
\hline 17 & Yalu & AS & 2010 & Heavy rain & $0.16 /-0.34$ & $-0.14 / 0.32$ & N/A \\
\hline 18 & Indus & AS & 2010 & Heavy rain & $0.20 /-0.27$ & $0.17 /-0.31$ & E \\
\hline 19 & Fitzroy & OC & 2010 & Heavy rain & $-0.09 / 0.64$ & $-0.39 / 0.47$ & S \\
\hline 20 & Murrumbidge, Murray & OC & 2012 & Heavy rain & $0.35 /-0.14$ & $-0.33 / 0.17$ & N/A \\
\hline 21 & Niger & AF & 2010 & Heavy rain & $-0.15 / 0.37$ & $-1.84 /-0.72$ & S \\
\hline 22 & Okavango & AF & 2011 & Heavy rain & $0.61 / 0.22$ & $-0.17 / 0.37$ & N/A \\
\hline
\end{tabular}

Note: AF Africa, AS Asia, EU Europe, SA South America, NA North America, OC Oceania, N/A not available

et al. 2011). Comparison of ensemble mean of precipitation showed increase in Songhua in 2013 and Indus in 2010, but decrease in other basins (Fig. S7), indicating the effect of seasonal or extreme precipitation. The effects of anthropogenic warming on three snow-induced floods were enhanced (the Fraser in 2012, Sava in 2010 and Volga in 2012) within a $90 \%$ likely range.

By contrast, flooding was suppressed in six flood events, but the anthropogenic influence on the occurrence of floods was not clear, with a negative $\mathrm{FAR}_{50}$ and positive $F_{A R}$. No significant signal was found in eight events.

Of the eight snow-induced flood events analyzed, three were enhanced and four were suppressed, indicating that the effects of climate change are more likely to be seen in the snow-induced floods. Three snow-induced floods were enhanced (the Fraser in 2012, Sava in 2010, and Volga in 2012), which is due to increased precipitation (Fig. S7). Two snow-induced floods (the Red in 2011 and Missouri in 2011) were suppressed, despite the increased precipitation (Fig. S7), may be due to decreased snow and earlier snowmelt peaks due to warming (Fig. S9).

Corresponding to the above results, comparison of the CDF and probability density function (PDF) of the annual maximum daily discharge showed that flood occurrence in a certain year was intensified by anthropogenic global warming, with the ALL experiments distributed to the right of the NAT-dtr and NAT-cimp5 experiments (Fig. S6). The figure also showed that floods were more likely to occur in eight rivers (Mackenzie in 2012, Peace in 2011, Fraser in 2012, Saskatchewan in 2013, Red in 2011, Missouri in 2011, Mississippi in 2011, and Magdalena in 2011) due to natural internal fluctuations, without considering global warming since the CDF/PDF of NAT-dtr and NAT-cmip5 are also distributed to the right of the ALL-LNG experiment. 


\subsection{Global analysis of anthropogenic effects on the occurrence of flooding}

The average $\mathrm{FAR}_{50}$ on a global scale shows clear regional characteristics. The results showed that the occurrence of floods was enhanced by anthropogenic radiative forcing during the target years (2010-2013) in wide areas at northern high latitudes including in a wide area of northern Eurasia, part of northwestern India and central Africa, while the occurrence of floods was suppressed in part of northeastern Eurasia, southern Africa, central to eastern North America and South America (Fig. 2). The main reason for the enhancement was increased precipitation in ALL compared with the NAT experiments (Fig. 3, Fig. S7). Despite the increased annual precipitation in the ALL experiment compared to the NAT experiments, the occurrence of flooding was suppressed or had small signals in northern USA and in Uruguay. One possible reason is that the warmer temperature in ALL reduced precipitation as snow and the peak snowmelt in these regions, as indicated by the suppression of the flood events in the Red and Mississippi Rivers (Table 2). In northeastern Russia, eastern Asia, southern USA, and eastern Australia, there were several basins with decreasing annual precipitation but enhanced flood occurrence, indicating that increasing heavy precipitation due to warming climate exacerbated flooding in these regions. These inconsistencies between changes in precipitation and the occurrence of floods support the importance of climate change studies using river discharge, rather than precipitation, to project future flood risk.
Interestingly, the pattern of positive and negative FAR values was not always in the same direction of change as the past observed flood trends. However, both FAR and the flood trend showed increasing signals in some rivers, e.g., increasing in eastern Eurasia and northwestern Europe, but decreasing in central to eastern North America, corresponding to previous studies on observed extreme discharge changes (Do et al. 2017).

The overall enhancement of the occurrence of flooding in northern Eurasia (Fig. 2) was consistent with the increase in floods under future climate seen in previous studies (Dankers et al. 2014; Hirabayashi et al. 2013), implying the potential to detect the effects of climate change on flood occurrence in these regions. By contrast, western Eurasia showed enhanced flooding during 2010-2013, inconsistent with the published projected reduction in the probability of flood occurrence in the future climate. The average FAR $_{50}$ for 2010-2013 shows the impact of anthropogenic radiative forcing on the recent climate, but is not necessarily consistent with future flood projections. One possible explanation for the inconsistency in eastern Europe is that the increased precipitation (Fig. 3) associated with more vapor transferred to higher latitudes due to the warmer climate currently dominates the effect of snowfall reduction due to warming. In a previous far future (2071-2100) projection (Hirabayashi et al. 2013), the effect of less snowfall due to warming may have dominated, and the resulting frequency of snowmelt flood was projected to decrease.

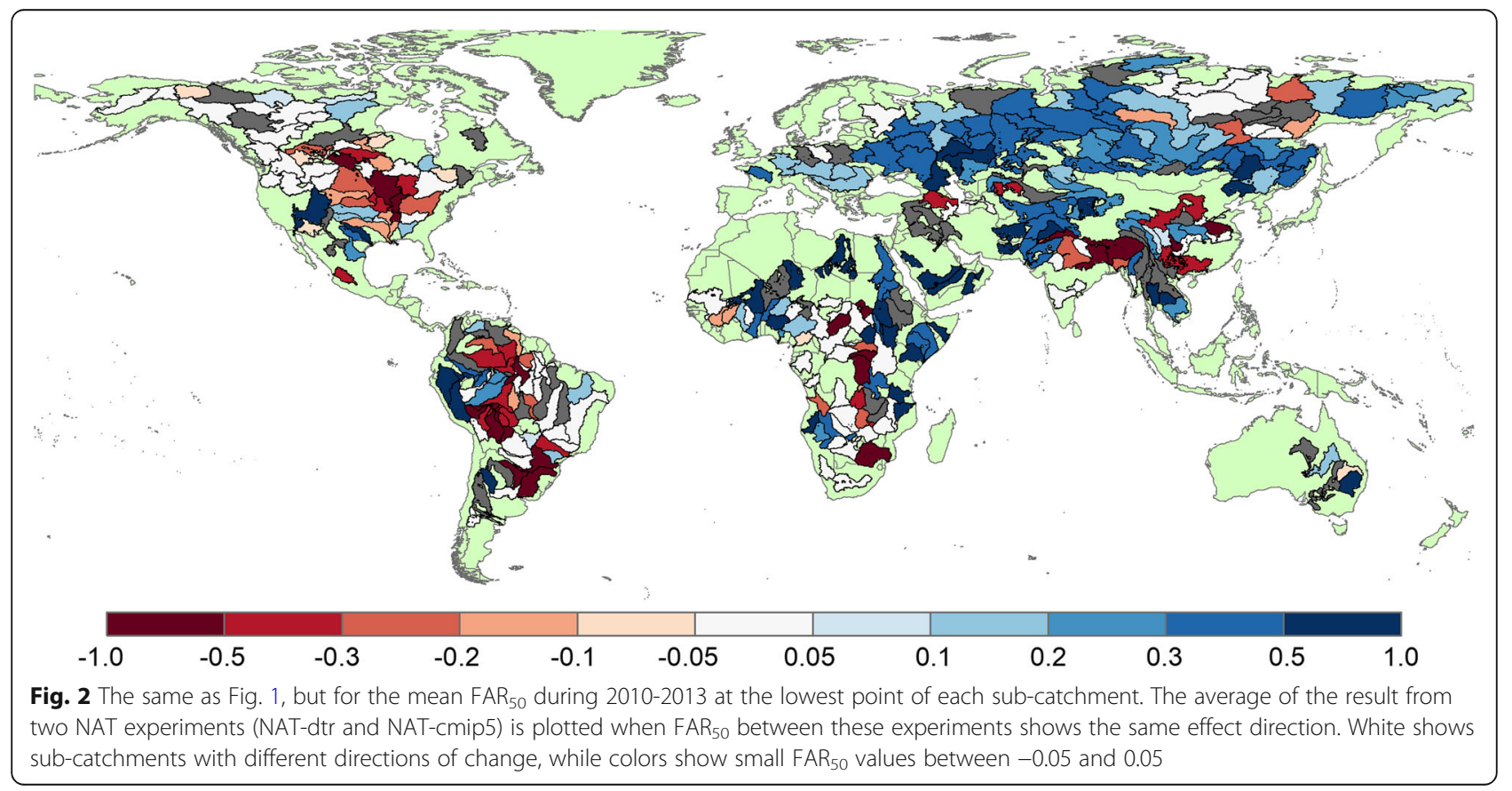




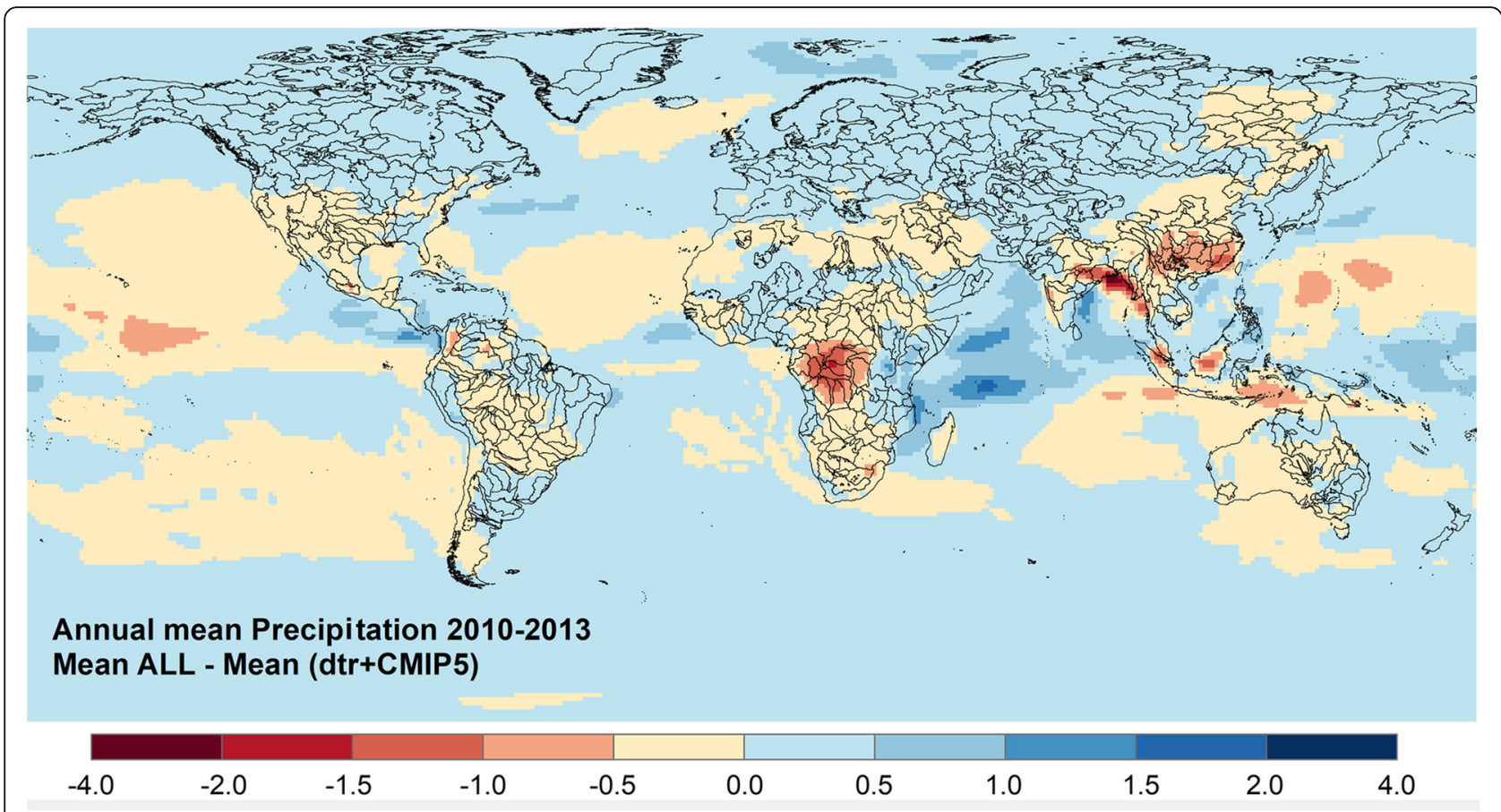

Fig. 3 Difference in the average annual precipitation ( $\mathrm{mm} /$ day) between the ALL and NAT (average of NAT-dtr and NAT-cmip5) experiments for 2010-2013

Considering historical variability, the estimated time required to detect plausible changes in discharge is several decades (Hirabayashi et al. 2005; Ziegler et al. 2003). Together with the limitations in the data length of in situ observations, the climate change signal can be detected later. Therefore, large ensemble simulation is a powerful method to detect anthropogenic radiative forcing on flooding and bridge our knowledge gap before the climate change signal can be detected.

The large ensemble climate was simulated using a single general circulation model; therefore, uncertainty associated with the specific climate model is expected. We focused on relatively large river basins at the subcatchment scale, but the sensitivity of flood frequency to climate change and the associated hydro-meteorological changes would vary with basin sizes. A previous study (Sharma et al. 2018) indicated that the changes in evapotranspiration or soil wetness due to a warming climate have greater effects on flood change in larger basins. Since flood changes are more closely connected to changes in extreme precipitation in smaller basins, which our model could not resolve due to the limited horizontal resolution of the models, analysis using finer spatial scales is required to assess small catchments. Overall, we analyzed the annual maximum daily discharge exceeding the magnitude of a 10-year flood as a proxy of flooding. Although a 10-year flood is statistically larger than normal conditions, the severity of the hazard varies with the basin characteristics, including local flood protection standards.

Due to the limited period covered by the large ensemble experiment (2010-2013), we analyzed only 22 flood events. Long-term experiments and a more comprehensive analysis of flood signals are required to confirm the detectability of flood changes.

\section{Conclusions}

The event attribution of historical flood events showed that anthropogenic climate change affected 64\% (14 of 22) of the floods analyzed, with increased occurrence caused by heavy rainfall, and increased or decreased snowmelt flood events. The occurrence of all but one event of snow-induced floods analyzed was affected by anthropogenic climate change, indicating that the effects of climate change are more likely to be seen in the snow-dominant rivers. A global-scale analysis of flood frequency revealed that anthropogenic climate change enhanced the occurrence of floods during 2010-2013 in a wide area of northern Eurasian, part of northwestern India, and central Africa, while it suppressed the occurrence of floods in part of northeastern Eurasia, southern Africa, central to eastern North America, and South America over the same period. Moreover, the differences in the occurrence of floods between climate experiments with and without anthropogenic climate change are the result of several hydrological processes such as snow 
melt and changes in seasonal and extreme precipitation depending on the climate zone and basin size. Thus, large ensemble discharge simulations can offer insight into anthropogenic effects on fluvial floods.

\section{Supplementary Information}

The online version contains supplementary material available at https://doi. org/10.1186/s40645-021-00431-w.

Additional file 1: S1. Event attribution experiments. S2. Selection of historical flood events between 2010 and 2013. S3. Extreme distribution function. Table S1. Summary of selected flood events between 2010 and 2013. The effects of anthropogenic climate change on flood events ( $E$, enhanced; S, suppressed; N/A, no significant effect) were judged as $E$ (S) when both percentile of fraction of attribution (FAR50) scores between ALL and NAT_dtr (dtr) and those between ALL and NAT CMIP5 (CMIP5) show the same signal. Fig. S1. Results of the evaluation of the fraction of attribution risk based on a bootstrap method. Fig. S2. Scatter plot of the annual maximum discharge derived from GRDC and global daily discharge reanalysis based on the 136 GRDC stations. Geographic location of the stations are shown in Fig. . Fig. S3. Correlation of annual max discharge derived from GRDC and global daily discharge reanalysis at 136 GRDC stations. Fig. S4. Comparisons of the annual maximum daily discharge derived from observations (GRDC), discharge reanalysis (S14FD), and ALL-LNG experiments. Fig. S5. The cumulative distribution function of annual maximum daily discharge for 22 events derived from observations (GRDC), discharge reanalysis (S14FD), and ALL-LNG experiments. Shade indicates maximum and minimum range among 650 ALLLNG experiments. Fig. S6. The probability density function and cumulative distribution function of annual maximum daily discharge for 22 events derived from event attribution experiments (ALL, ALL-LNG, NAT$d t$, and NAT-CMIP5). The orange dot line indicates magnitude of 10-year flood in ALL-LNG experiment. Fig. S7. Difference of average annual precipitation between ALL and mean of NAT (NAT-dtr and NAT-cmip5) experiments for selected flood events (mm/day). Fig. S8. Same for Fig 3 but the difference between ALL and NAT-cmip5 (a) and ALL and NAT-dtr (b). Fig. S9. Difference of average annual temperature (K). Difference between ALL and NAT-cmip5 (a), ALL and NAT-dtr (b), and ALL and NAT (average of NAT-dtr and NAT-cmip5) (c) experiments. Average for 20102013 are shown. Fig. S10. Difference of mean annual 5th largest daily rainfall. Difference between ALL and NAT-cmip5 (a), ALL and NAT-dtr, and ALL and average of NAT-dtr and NAT-cmip5 experiments for 2010-2013 are shown.

\section{Acknowledgements}

We thank A.S, A.T., and H.M. for their assistance in our experiments.

\section{Authors' contributions}

H.A, Y.I, H.S., and Y.K. carried out numerical simulations and data analysis. D.Y. carried out model development and evaluation. Y.H. designed the research and wrote the paper. The authors read and approved the final manuscript.

\section{Funding}

This research was supported by the Environment Research and Technology Development Fund (JPMEERF20202005) of the Environmental Restoration and Conservation Agency of Japan, a JSPS Grant-in-Aid for Scientific Research (18H01540), the Integrated Research Program for Advancing Climate Models (TOUGOU) (JPMXD0717935457) from the Ministry of Education, Culture, Sports, Science and Technology (MEXT), Japan, and MS\&AD InterRisk Research \& Consulting, Inc.

\section{Availability of data and materials}

The flood trend data in sub-catchments used for drawing the figures are available for research purpose by requests.

\section{Declarations}

\section{Competing interests}

The authors declare that they have no competing interests.

\section{Author details}

'Department of Civil Engineering, Shibaura Institute of Technology, 3-7-5 Toyosu, Koto-ku, Tokyo 135-8548, Japan. ${ }^{2}$ Institute of Industrial Science, The University of Tokyo, 4-6-1 Komaba, Meguro-ku, Tokyo 153-8505, Japan. ${ }^{3}$ Meteorological Research Institute, 1-1 Nagamine, Tsukuba, Ibaraki 305-0052, Japan. ${ }^{4}$ National Institute for Environmental Studies, 16-2 Onogawa, Tsukuba, Ibaraki 305-0053, Japan. ${ }^{5}$ Corporate Planning Department, MS\&AD InterRisk Research \& Consulting, Inc., 2-105, Kanda Awajicho, Chiyoda-ku, Tokyo 101-0063, Japan.

Received: 30 October 2020 Accepted: 24 May 2021

Published online: 15 June 2021

\section{References}

Bloeschl G, Hall J, Viglione A, Perdigao RAP, Parajka J, Merz B, Lun D, Arheimer B, Aronica GT, Bilibashi A, Bohac M, Bonacci O, Borga M, Canjevac I, Castellarin A, Chirico GB, Claps P, Frolova N, Ganora D, Gorbachova L, Gul A, Hannaford J, Harrigan S, Kireeva M, Kiss A, Kjeldsen TR, Kohnova S, Koskela JJ, Ledvinka O, Macdonald N, Mavrova-Guirguinova M, Mediero L, Merz R, Molnar P, Montanari A, Murphy C, Osuch M, Ovcharuk V, Radevski I, Salinas JL, Sauquet E, Sraj M, Szolgay J, Volpi E, Wilson D, Zaimi K, Zivkovic N (2019) Changing climate both increases and decreases European river floods. Nature 573:108

Dankers R, Arnell NW, Clark DB, Falloon PD, Fekete BM, Gosling SN, Heinke J, Kim H, Masaki Y, Satoh Y, Stacke T, Wada Y, Wisser D (2014) First look at changes in flood hazard in the Inter-Sectoral Impact Model Intercomparison Project ensemble. Proc Natl Acad Sci USA 111(9):3257-3261. https:/doi.org/10.1073/ pnas.1302078110

Do HX, Westra S, Leonard M (2017) A global-scale investigation of trends in annual maximum streamflow. J Hydrol 552:28-43. https://doi.org/10.1016/j. jhydrol.2017.06.015

Dottori F, Szewczyk W, Ciscar J-C, Zhao F, Alfieri L, Hirabayashi Y, Bianchi A, Mongelli I, Frieler K, Betts RA, Feyen L (2018) Increased human and economic losses from river flooding with anthropogenic warming. Nat Climate Change 8:781

Dunn RJH, Alexander LV, Donat MG, Zhang X, Bador M, Herold N, et al. (2020). Development of an updated global land in situ based data set of temperature and precipitation extremes: HadEX3. Journal of Geophysical Research: Atmospheres, 125, e2019JD032263. https://doi.org/10.1029/201 9JD032263

Efron B, Tibshirani R (1993) An introduction to the bootstrap. Chapman and Hall, London. https://doi.org/10.1007/978-1-4899-4541-9

EMDAT. The OFDA/CRED international disaster database, University Catholic Louvain-Brussels, Belgium. http://www.emdat.be. [January, 2019].

Gudmundsson L, Boulange J, Do H, Gosling S, Grillakis M, Koutroulis A, Leonard M, Liu J, Schmied H, Papadimitriou L, Pokhrel Y, Seneviratne S, Satoh Y, Thiery W, Westra S, Zhang X, Zhao F (2021) Globally observed trends in mean and extreme river flow attributed to climate change. Science 371:1159

Hartmann DL, Klein Tank AMG, Rusticucci M, Alexander LV, Brönnimann S, Charabi Y, Dentener FJ, Dlugokencky EJ, Easterling DR, Kaplan A, Soden BJ, Thorne PW, Wild M, Zhai PM (2013) Observations: Atmosphere and Surface. In: Stocker TF, Qin D, Plattner G-K, Tignor M, Allen SK, Boschung J, Nauels A, Xia Y, Bex V, Midgley PM (eds) Climate change 2013: the physical science basis. Contribution of Working Group I to the Fifth Assessment Report of the Intergovernmental Panel on Climate Change. Cambridge University Press, Cambridge and New York

Hirabayashi Y, Kanae S, Struthers I, and Oki T. (2005), A 100-year (1901? 2000) global retrospective estimation of the terrestrial water cycle, J. Geophys. Res. 110, D19101, https://doi.org/10.1029/2004JD005492

Hirabayashi Y, Mahendran R, Koirala S, Konoshima L, Yamazaki D, Watanabe S, Kim H, Kanae S (2013) Global flood risk under climate change. Nat Climate Change 3(9):816-821. https://doi.org/10.1038/nclimate1911

Hirabayashi Y, Tanoue M, Sasaki O, Zhou XD, and Yamazaki D. (2021). Global exposure to flooding from the new CMIP6 climate model projections. Sci Rep. 11. https://doi.org/10.1038/s41598-021-83279-w

lizumi T, Takikawa H, Hirabayashi Y, Hanasaki N, Nishimori M (2017) Contributions of different bias-correction methods and reference meteorological forcing 
data sets to uncertainty in projected temperature and precipitation extremes. J Geophys Res Atmospheres 122(15):7800-7819. https://doi.org/10.1002/201 7JD026613

Imada Y, Kawase H, Watanabe M, Arai M, Shiogama H, Takayabu I (2020) Advanced risk-based event attribution for heavy regional rainfall events. Npj Climate Atmospheric Sci 3:37. https://doi.org/10.1038/s41612-020-00141-y

Koirala S, Yeh PJ-F, Hirabayashi Y, Kanae S, Oki T (2014) Global-scale land surface hydrologic modeling with the representation of water table dynamics. J Geophys Res Atmospheres 119(1):75-89. https://doi.org/10.1002/2013JD0203 98

Lewis SC, Karoly DJ (2013) Anthropogenic contributions to Australia's record summer temperatures of 2013. Geophys Res Lett 40(14):3705-3709. https:// doi.org/10.1002/grl.50673

Li R, Li D, Nanding N, Wang X, Fan X, Chen Y, Tian F, Tett SFB, Dong B, Lott FC (2021) Anthropogenic influences on heavy precipitation during the 2019 extremely wet rainy season in Southern China. Bull Amer Meteor Soc. 102(1): S103-S109. https://doi.org/10.1175/BAMS-D-20-0135.1

Madsen H, Lawrence D, Lang M, Martinkova M, Kjeldsen T (2014) Review of trend analysis and climate change projections of extreme precipitation and floods in Europe. J Hydrol 519:3634-3650. https://doi.org/10.1016/j.jhydrol.2014.11. 003

Milly PCD, Betancourt J, Falkenmark M, Hirsch RM, Kundzewicz ZW, Lettenmaier DP, Stouffer RJ (2008) Climate change - Stationarity is dead: whither water management? Science 319:573-574

Min S-K, Zhang X, Zwiers FW, Hegerl GC (2011) Human contribution to moreintense precipitation extremes. Nature 470(7334):378-381. https://doi.org/10.1 038/nature09763

Otto FEL, Massey N, van Oldenborgh GJ, Jones RG, and Allen MR. (2012). Reconciling two approaches to attribution of the 2010 Russian heat wave. Geophys Res Lett. 39, L04702. https://doi.org/10.1029/2011GL050422

Pall P, Aina T, Stone DA, Stott PA, Nozawa T, Hilberts AGJ, Lohmann D, Allen MR (2011) Anthropogenic greenhouse gas contribution to flood risk in England and Wales in autumn 2000. Nature 470(7334):382-385. https://doi.org/10.103 8/nature09762

Rayner NA, Parker DE, Horton EB, Folland CK, Alexander LV, Rowell DP, Kent EC, and Kaplan A. (2003) Global analyses of sea surfacetemperature, sea ice, and night marine air temperature since the late nineteenth century. J Geophys Res Atmospheres., 108, D14, 4407, https://doi.org/10.1029/2002JD002670

Sharma A, Wasko C, Lettenmaier DP (2018) If precipitation extremes are increasing, why aren't floods? Water Resour Res 54(11):8545-8551. https://doi. org/10.1029/2018WR023749

Shiogama H, Watanabe M, Imada Y, Mori M, Ishii M, Kimoto M (2013) An event attribution of the 2010 drought in the South Amazon region using the MIROC5 model. Atmospheric Sci Lett 14(3):170-175. https://doi.org/10.1002/a sl2.435

Shiogama H, Watanabe M, Imada Y, Mori M, Kamae Y, Ishii M, Kimoto M (2014) Attribution of the June-July 2013 Heat Wave in the Southwestern United States. Sola 10(0):122-126. https://doi.org/10.2151/sola.2014-025

Sippel S, Otto FEL (2014) Beyond climatological extremes - assessing how the odds of hydrometeorological extreme events in South-East Europe change in a warming climate. Climatic Change 125(3-4):381-398. https://doi.org/10.1 007/s10584-014-1153-9

Stott PA, Stone DA, Allen MR (2005) Human contribution to the European heatwave of 2003 (vol 432, pg 610, 2004). Nature 436(7054):1200-1200. https://doi.org/10.1038/nature04099

Takata K, Emori S, Watanabe T (2003) Development of the minimal advanced treatments of surface interaction and runoff. Glob Planet Change 38(1-2): 209-222. https://doi.org/10.1016/S0921-8181(03)00030-4

Trenberth K, Fasullo J, Shepherd T (2015) Attribution of climate extreme events. Nat Climate Change 5(8):725-730. https://doi.org/10.1038/nclimate2657

Villarini G, Serinaldi F, Smith JA, and Krajewski WF. (2009). On the stationarity of annual flood peaks in the continental United States during the 20th century. Water Resour Res. 45, W08417, https://doi.org/10.1029/2008WR007645

Watanabe M, Suzuki T, O'Ishi R, Komuro Y, Watanabe S, Emori S, Takemura T, Chikira M, Ogura T, Sekiguchi M, Takata K, Yamazaki D, Yokohata T, Nozawa T, Hasumi H, Tatebe H, Kimoto M (2010) Improved climate simulation by MIROC5. Mean States Variability, and climate sensitivity. J Climate 23:63126335

Yamazaki D, Kanae S, Kim H, and Oki T. (2011). A physically based description of floodplain inundation dynamics in a global river routing model. Water Resour Res. 47, W04501, https://doi.org/10.1029/2010WR009726
Ziegler AD, Sheffield J, Maurer EP, Nijssen B, Wood EF, Lettenmaier DPL (2003) Detection of intensification in global- and continental-scale hydrological cycles: temporal scale of evaluation. J Climate 16:535-547

\section{Publisher's Note}

Springer Nature remains neutral with regard to jurisdictional claims in published maps and institutional affiliations.

\section{Submit your manuscript to a SpringerOpen ${ }^{\circ}$ journal and benefit from:}

- Convenient online submission

- Rigorous peer review

- Open access: articles freely available online

- High visibility within the field

- Retaining the copyright to your article

Submit your next manuscript at $\boldsymbol{\sim}$ springeropen.com 